\title{
Testing of Efficient Market Hypothesis in the Emerging Capital Markets: Evidence from India
}

\author{
${ }^{1}$ Mr. Mohd.Mubasher Hassan, ${ }^{2}$ Prof. Mouh-i-Din Sangmi \\ Research Scholar Deptt. of Business \& Financial Studies University of Kashmir, \\ Professor \& Head Deptt. of Business \& Financial Studies University of Kashmir.
}

\begin{abstract}
With the wave of globalization across the countries, the capital markets got integrated, this integration led to new developments in the securities market of both developed and developing countries. The emerging economies specially witnessed a metamorphosis in their markets probably due to new initiatives of liberalisation,privatization, globalization,de-materilisation,transparency and so on. All this helped the flow of information from companies to market and vice-versa, faster and efficient, which determine the investor's decision making in the capital market. The present study is an attempt to investigate the efficiency of Efficient Market Hypothesis in the context of Indian securities market. The aim of this study is to analyses whether prices in stocks in capital market follow a random walk process or not. The study is based on the six most significant indices of Indian stock market viz. Sensex 30,BSE 100,BSE 200,BSE 500,BSE Midcap and BSE Small cap.The behavior of these indices has been observed during the period (Jan 1991-August 2013).
\end{abstract}

Key Words: Efficient Market hypothesis, Random Walk Theory, Indian Capital Market, Bombay Stock Exchange.

\section{Introduction}

In Financial literature the term stock market efficiency is used to explain the relationship between information and share prices in the capital market of any economy. Fama (1970 and 1991) provides the formal definition of "Market Efficiency". He classifies market efficiency into three categories namely, weak-form, semi strong-form and strong-form. In its weak form, Efficient Market Hypothesis (EMH) states that the stock returns are serially un-correlated and have a constant mean. In other words, a market is considered weak form efficient if current prices fully reflect all information contained in historical prices, which implies that no investor can devise a trading rule based solely on past price patterns to earn abnormal returns. A market is semi strong efficient if stock prices instantaneously reflect any new publicly available information and Strong form efficient if prices reflect all types of information whether available publicly or privately. Thus in an efficient capital market, past information is of no use in predicting future prices and the market should react only to new information.

Market Efficiency has an influence on the investment strategy of an investor because Since in an efficient market, the prices of securities will reflect the market's best estimate of their expected return and risk, taking into account all that is known about them. Therefore, there will be no undervalued securities offering higher than deserved expected returns, given their risk. So, in an efficient market, an investment strategy concentrating simply on the overall risk and return characteristics of the portfolio will be more sensible. If however, markets are not efficient, and excess returns can be made by correctly picking winners, then it will pay investors to spend time finding these undervalued securities, Rutterford(1983).

\section{Review of literature}

Fama (1970) argued that in an active market of large numbers of well-informed and intelligent investors,stocks will be appropriately priced and reflect all available information. In these circumstances, no information or analysis can be expected to result in out-performance of an appropriate benchmark. Because of the wide availability of public information, it is nearly impossible to beat the market consistently.

Sunil (1996) provides empirical evidence on weak form efficiency and the day of the week effect in Bombay Stock Exchange over a period of 1987-1994. The results provide evidence of day of the week effect and that the stock market is not weak form efficient.

Mitra (2000) developed ANN model based on past stock market prices as parameters and showed that network performs very well I forecasting developments in BSE sensitive index, thus rejecting the criteria of unforcastibility of stock prices in BSE.Ming et al.(2000) also tries to disprove random walk by establishing the predictive capability of technical rules like Variable Moving Average (VMA) and Fixed Length Moving Average (FMA), this study shows that variance ratio and multiple variance ratio tests reject random walk for Kuala Lumpur stock exchange.Researchers further show that trading rules like variable lag moving average (VMA) and fixed length moving average (FMA) have predictive ability of earning profits over and above the transaction 
costs.

Meredith Beechey et al.(2000) in this paper, authors discuss the main ideas behind the efficient market hypothesis, and provide a guide as to which of its predictions seem to be borne out by empirical evidence, and which do not. In examining the empirical evidence, they concentrate on the stock and foreign exchange markets. The evidence suggests, however, that it cannot explain some important and worrying features of asset market behaviour.Most importantly for the wider goal of efficient resource allocation, financial market prices appear at times to be subject to substantial misalignments, which can persist for extended periods of time.

Ramasastri (2001) conducted a study on stock market efficiency spectral analysis. This research studies efficiency of Indian stock market since the beginning of 1996 to 1998 using a powerful technique-spectral analysis. Correlogram, based on Sensex, establishes that Indian stock market has been efficient, Spectral analysis finds that there is a presence of periodic cycles in the movements of share prices. Thus, confirms market efficacy as power function flatten at higher frequencies. In the post reforms era (after 1991) in a period where stock market has become mature (after 2001), the efficiency of capital market in India assume greater importance as the trend of investment is growing as a result of regulatory reforms and removal of other barriers for the entry of foreign high networth and institution investors. It is against this back drop the present study has been undertaken to test the efficiency of the Indian capital market.

Pant et al.(2002) conducted a research on Testing Random Walk hypothesis for Indian stock market Indices. While analyzing the behavior of daily and weekly returns of 5 Indian market indices for random walk during April 1996-June 2001, it shows that the Indian stock market indices do not follow random walk.

Lucio Sarno, L.Daniel (2003) this study extends this literature by showing that if the SVAR includes one or more variables that are efficient in the strong form of the efficient market hypothesis, the identifying restrictions frequently imposed in SVARs cannot be satisfied. The paper argue that the analysis will likely apply to VARs that include variables that are consistent with the weaker form of the efficient market hypothesis, especially when the data are measured at the monthly or quarterly frequencies.

Allan Timmermann, Clive W.J (2004) examine that forecasters constantly search for predictable patterns and affect prices when they attempt to exploit such trading opportunities. Thence stable forecasting patterns are therefore unlikely to persist for long periods of time and will self-destruct when discovered by a large number of investors. This gives rise to non-stationarities in the time series of financial returns and complicates both formal tests of market efficiency and the search for successful forecasting approaches.

Abdulnasser (2009) this paper tests for informational efficiency in the Australian stock market. Using daily data for the period 1994-2006, test were carried out using robust methods that are not sensitive to either non-normality in the data or the presence of ARCH effects. Authors found that the share price index has one unit root, which implies that the changes in the share price index are totally random. This finding is consistent with the weak form of market efficiency and earlier studies (Henry and Olekalns, 2002; Chaudhuri and Smiles, 2004; Hatemi-J, 2004a, b).

Hashem Pesaran (2010) the paper is focuses on the theoretical foundation of the EMH, and show that market efficiency could co-exit with heterogeneous beliefs and individual irrationality so long as individual errors are cross sectionally weakly dependent in the sense defined by Chudik, Pesaran, and Tosetti (2010). But at times of market euphoria or gloom these individual errors are likely to become cross sectionaly strongly dependent and the collective outcome could display significant departures from market efficiency but, it is likely to be punctuated with episodes of bubbles and crashes.

Phil Simmons (2010) the author studies n Differential Evolutionary Algorithm (DEA) that is can supposedly violate the weak form of the Efficient Markets Hypothesis is tested using daily data from the Australian share market from 2000 until 2008. The paper concludes speculators may make supernormal profits from new methodologies however that such profits are unlikely to be sustained.

Saqib and Mohammad (2012) examined the weak form of efficient market hypothesis on the four major stock exchanges of South Asia including, India, Pakistan, Bangladesh and Sri Lanka. Historical index values on a monthly, weekly and daily basis for a period of 14 Years (1997-2011) were used for analysis. They applied four statistical tests including runs test, serial correlation, unit root and variance ratio test. The findings suggest that none of the four major stock markets of south-Asia follows Random-walk and hence all these markets are not the weak form of efficient market.

C.Nguyen et al (2012) this empirical study investigates whether the Taiwan Stock market is weakly efficient by modifying and estimating Dockery and Kavussanos' multivariate model using a set of panel data. The Taiwan equity market is characterized as high-tech, one of the most liquid markets on the globe, well and strictly regulated, and in an advanced emerging economy. However, the empirical findings suggest that the Taiwan stock market is not informationally efficient, which may be attributable to the lack of broadness and depth of the market. 


\section{Objective of the Study}

To investigate whether prices of stocks in BSE follow a Random Walk process as required by the market efficiency theory.

\section{Research Methodology \& Data}

This Study is based on a case study of BSE where the Closing value of indices, viz., SENSEX30,BSE100,BSE 200,BSE 500,BSE small cap and BSE midcap have been taken as variables for the purpose of analysis and the data taken for the study range from January 1991 - August 2013. Secondary data is used for the study and the data on monthly prices is collected form bseindia.com for all indices.

To analyze the data, statistical tools like Kolmogorov-Smirnov test, Runs test, Serial correlation, Autocorrelation Function and Augmented-Dickey Fuller test are applied.

\section{Hypotheses}

Same hypothesis applies to all tests and data series.

$\mathrm{H}_{01}$ : The price movements in the share prices of Sensex are not affected by past prices.

$\mathrm{H}_{02}$ : The price movements in the share prices of BSE 100 are not affected by past prices.

$\mathrm{H}_{03}$ : The price movements in the share prices of BSE 200 are not affected by past prices.

$\mathrm{H}_{04}$ : The price movements in the share prices of BSE 500 are not affected by past prices.

$\mathrm{H}_{05}$ : The price movements in the share prices of Mid cap are not affected by past prices.

$\mathrm{H}_{06}$ : The price movements in the share prices of Small cap are not affected by past prices.

\section{Results and Discussion}

One of the basic assumptions underlying the random walk theory and, therefore, EMH is that if the stock prices are random then its distribution should be normal.

To understand this concept, the study has been discussed under the following heads:

i. Descriptive statistics;

ii. Frequency distributions;

iii. Kolmogorov - Smirnov Goodness of fit test;

iv. Runs test;

v. Serial test;

vi. Auto correlation function:

vii. Unit root test.

\section{Descriptive statistics}

Any normal distribution is an advantage because we need only two summary measures, mean and variance, to describe the entire distribution. Then is Jarque-Bera (JB) test of normality which is asymptotic, i.e applied to large samples where it first computes skewness and kurtosis measures and then calculates JB statistic with the joint null hypothesis that the data are normally distributed. If the computed JB statistic is low then probability value the null hypothesis is accepted i.e skewness and kurtosis is zero or vice versa.

Table: 1 Descriptive statistics

\begin{tabular}{|l|l|l|l|l|l|l|}
\hline & Sensex & BSE 100 & BSE 200 & BSE 500 & Mid cap & Small cap \\
\hline Mean & 7709.52 & 2283.39 & 929.37 & 3961.82 & 5124.79 & 6051.13 \\
\hline S.D & 5984.08 & 1863.24 & 758.33 & 2448.38 & 2005.80 & 2573.57 \\
\hline Kurtosis & -0.86 & -0.84 & -0.84 & -1.55 & -0.86 & -0.44 \\
\hline Skewness & 0.88 & 0.88 & 0.88 & 0.20 & -0.37 & -0.21 \\
\hline JB & 200.33 & 198.76 & 198.32 & 147.69 & 77.26 & 60.12 \\
\hline Prob. & 0.00 & 0.00 & 0.00 & 0.00 & 0.00 & 0.00 \\
\hline Range & 19526.77 & 6178.49 & 2526.20 & 7741.87 & 8837.22 & 12455.10 \\
\hline Minimum & 982.32 & 290.99 & 130.32 & 850.56 & 952.27 & 893.27 \\
\hline Maximum & 20509.09 & 6469.48 & 2656.52 & 8592.43 & 9789.49 & 13348.37 \\
\hline
\end{tabular}




\section{Frequency Distribution}

The Histograms of the indices is computed to ascertain whether the distribution of index values fits the normal distribution. A distribution that is not symmetric but has a tail toward on one end of the distribution than the other is called skewed. If the tail is toward larger values, the distribution is positively skewed or skewed to the right. If the tail is toward smaller values, the distribution is negatively skewed or skewed to the left. Kurtosis indicates the extent to which, for a given standard deviation, observations cluster around a central point. If, observations within a distribution cluster more than those in the normal distribution (that is the distribution is more peaked), the distribution is called leptokurtic. If, observations cluster less than in the normal distribution (that is, it is flatter), the distribution is termed platokurtic. Values for skewness and Kurtosis are 0 if the observed distribution is exactly normal.

As can be seen from Figures, that the frequency distributions is not normal in the indices under study. Skewness \& Kurtosis were observed to varying degrees \& that none of the index is said to have normal distribution as can be seen form below depicted diagrams. As is further confirmed by Jarque-Bera (JB) test where joint hypothesis of normality is rejected in all the cases. Thence by descriptive statistics given in Table 1 . The results indicate that the distribution is not normal and, therefore, the prices on BSE do not follow random walk.

Figure: 1 BSE Sensex

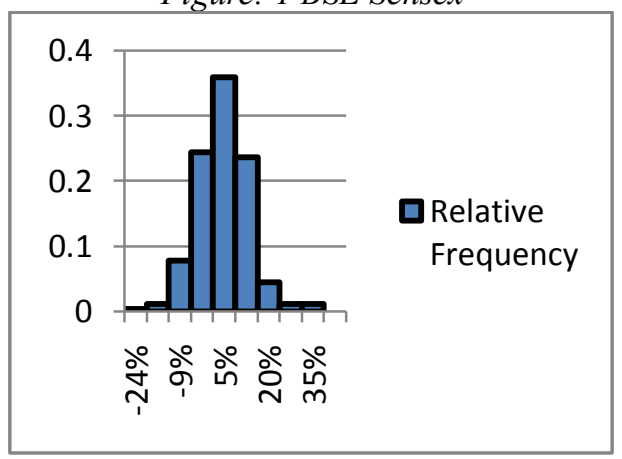

The distribution is slightly more peaked than normal

Figure: 2 BSE 100

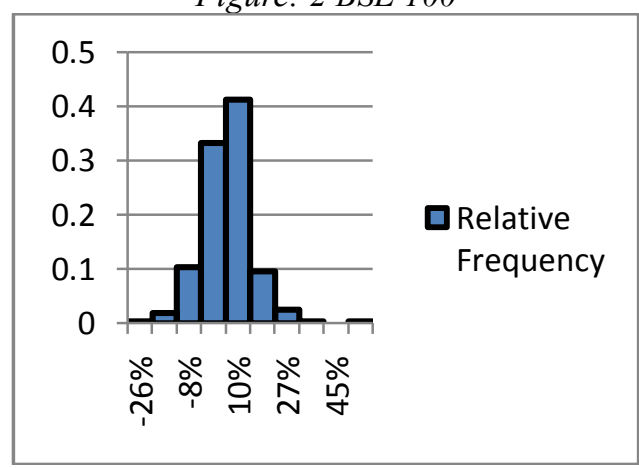

Distribution is positively skewed and leptokurtic

Figure: 3 BSE 200

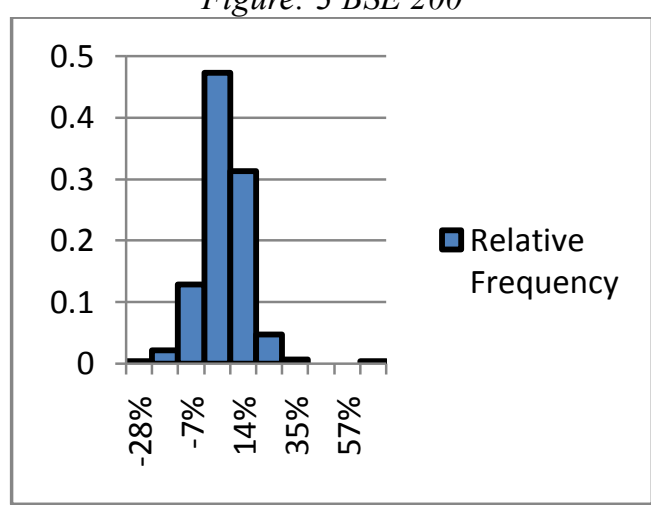

Distribution is positively skewed and leptokurtic 


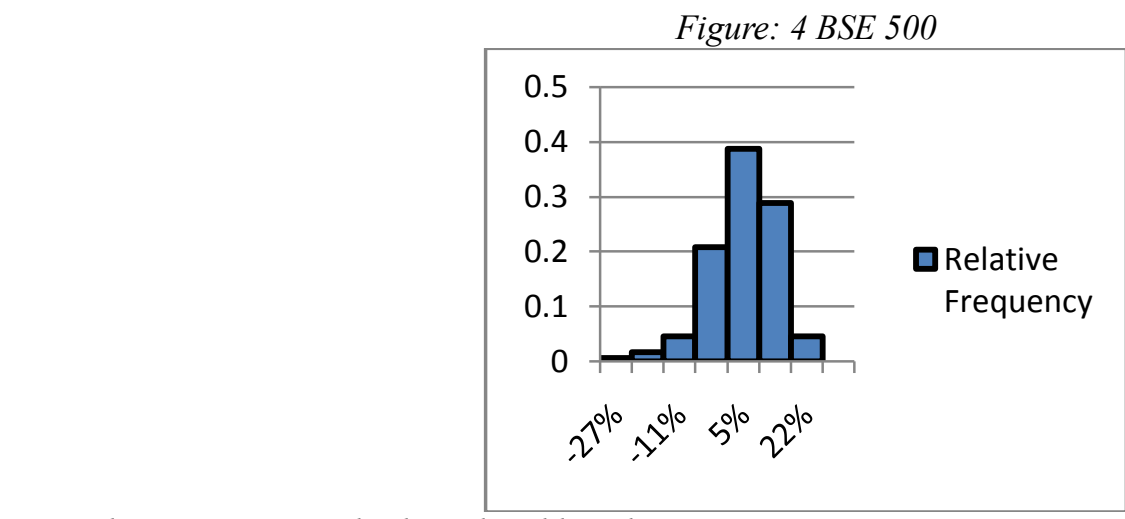

Distribution is negatively skewed and leptokurtic

Figure: 5 BSE Mid cap

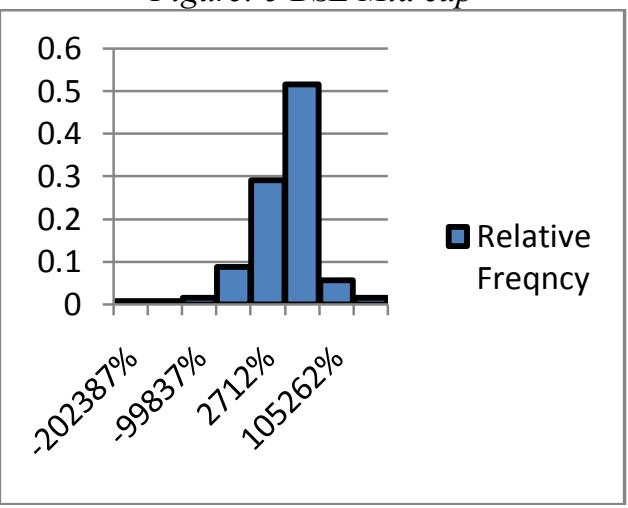

Distribution is negatively skewed and leptokurtic

Figure: 6 BSE Small cap

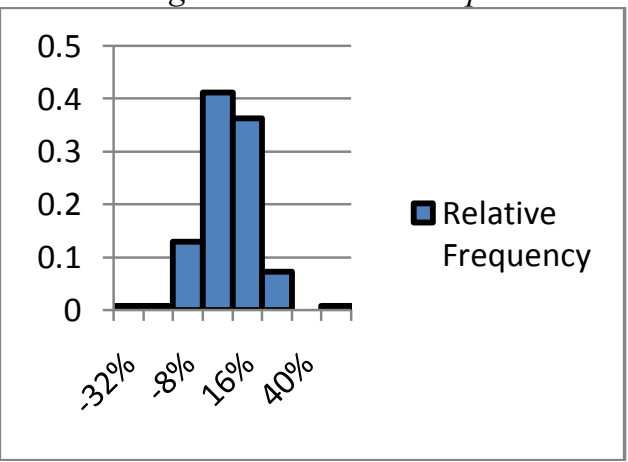

Distribution is negatively skewed and leptokurtic with some outiers

\section{Kolmogorov-Smirnov Goodness of fit Test}

The Kolmogorov-Smirnov one sample goodness of fit test compares the cumulative distribution function of a variable with a uniform or normal distributions and tests whether the distributions are homogeneous. In other words it is used to determine how well a random sample of data fit a particular distribution (uniform,normal).It is based on compares of the samples cumulative distribution against the standard cumulative function of each distribution. The Kolmogorov-Smirnov one sample goodness of fit test compares the cumulative distribution function for a variable with a uniform or normal distribution and tests whether the distribution are homogenous with the null hypothesis as, Distribution is normal. The table 2 below clearly indicate, that the frequency distribution of the monthly values of all the indices does not fit either normal or uniform distribution as null hypothesis is rejected in all the indices. As an be seen D-values are more than critical values. 


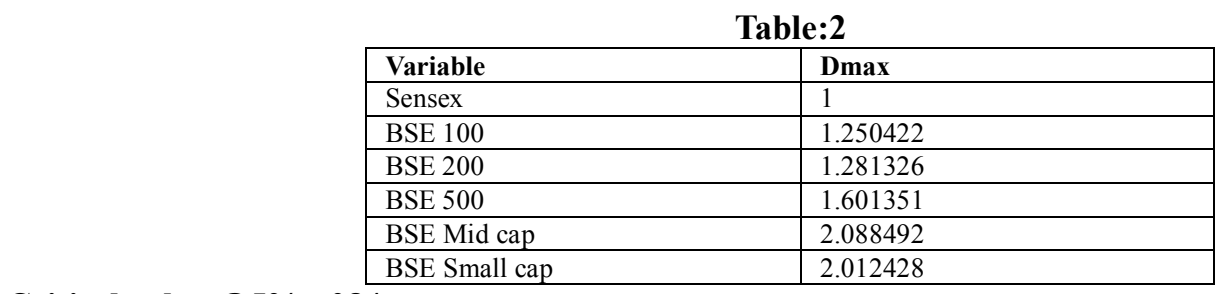

Critical value $@ 5 \%=.084$

\section{Critical value $@ 20 \%=.066$}

As the results clearly indicate that the frequency distribution of Indian stock market viz, BSE does not fit either normal or uniform distribution and hence it can't be said to exhibit efficiency in weak form, in other words prices are no said to follow random walk.

\section{Runs Test}

Second method used to test the market efficiency,

The test examines whether the value of one observation influences the values taken by later observations. If there is no influence the sequence is considered random. The table 3 shows the results of Run test,for monthly returns, the p- value for all variable indices is .000 which is clearly too small than alpha-(.05).Hence, we reject the null hypothesis, that observation are randomly generated i.e. for monthly succession returns are not randomly generated.

Table:3

\begin{tabular}{|l|l|l|}
\hline Variable & Z-value & p-value \\
\hline Sensex & -16.2417471 & 0.00 \\
\hline BSE 100 & -13.1117584 & 0.00 \\
\hline BSE 200 & -16.2420911 & 0.00 \\
\hline BSE 500 & -12.6147477 & 0.00 \\
\hline BSE Mid cap & -10.0551197 & 0.00 \\
\hline BSE Small cap & -9.47623233 & 0.00 \\
\hline
\end{tabular}

\section{Serial Test}

Serial correlation between current and previous series was analyzed through auto correlation. If the correlation between current return and previous return is significantly positive then we infer that there exists certain trend in return series. Hence there is non-randomness in data. If it is significantly negative then, we still infer that there is certain reverse relationship in return series, implying non-randomness in data, if correlation between current and previous return is zero, only then we can infer that there is randomness in return series. It is analyzed whether the average monthly return on any month $(\mathrm{t})$ correlates with the average monthly return on month $(t+1, t+2, t+3 \ldots \ldots t+n)$.if the markets are efficient then there would be an insignificant relation between return on month $(\mathrm{t})$ with the returns on month $(\mathrm{t}+1, \mathrm{t}+2, \mathrm{t}+3 \ldots \mathrm{t}+\mathrm{n})$. For testing significance of autocorrelation $\mathrm{D}$ $\mathrm{W}$ test was selected the value of D-W test static " $\mathrm{d}$ " always lies between 0 -4.If $\mathrm{d}$ is substantially less than 2, then there is evidence that series has positive autocorrelation, $\&$ if the " $\mathrm{d}$ " is substantially greater than 2 , then there is evidence that series has negative auto-correlation, As a rule of thumb , if $d$ is less than 1 signify strong positive correlation, greater than 3 signify strong negative correlation. The table 4 below represents the results of D-W test for monthly return series of the indices viz; Sensex, BSE 100,BSE200,BSE 500,BSE Mid cap,BSE Small cap. All the calculated D-W statics are approximately higher or lower than 2, hence positive or negative autocorrelation is present. In that case there is no randomness in data and market can't be said weak form efficient.

Table: 4

\begin{tabular}{|l|l|}
\hline Variable & D-value \\
\hline Sensex & 1.96542746 \\
\hline BSE 100 & 1.924704 \\
\hline BSE 200 & 1.89699 \\
\hline BSE 500 & 1.889404 \\
\hline BSE Mid cap & 1.782168 \\
\hline BSE Small cap & 1.8881804 \\
\hline
\end{tabular}

$\mathrm{d}$ is approx $=2$ implying that there is no autocorrelation of first order 


\section{Autcorrelation function}

The autocorrelation function (ACF) test is examined to identify the degree of autocorrelation in a time series. It measures the correlation between the current and lagged observations of the time series of stock returns. If time series has unit root, than the autocorrelation function slowly decrease starting from the value of one and the partial correlation function has only first value which differs from zero. By examining the correlogram in all the figures below we see that the autocorrelation coefficients start form very high values and their values decrease very slowly towards zero as $\mathrm{k}$ increases Thus by autocorrelation function we can make a conclusion that the indices of BSE series under study non stationary time series.

Figure: BSE Sensex
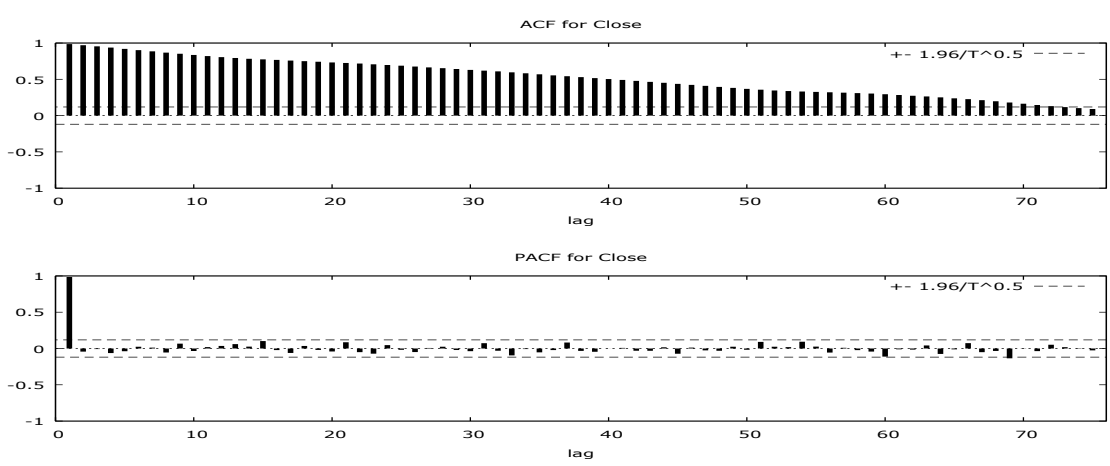

Figure: BSE 100

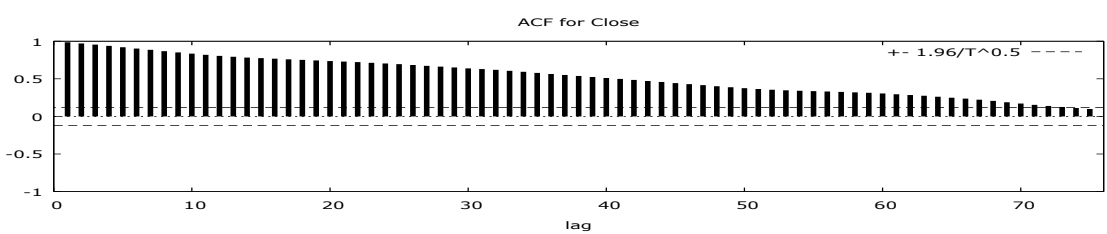

PACF for Close

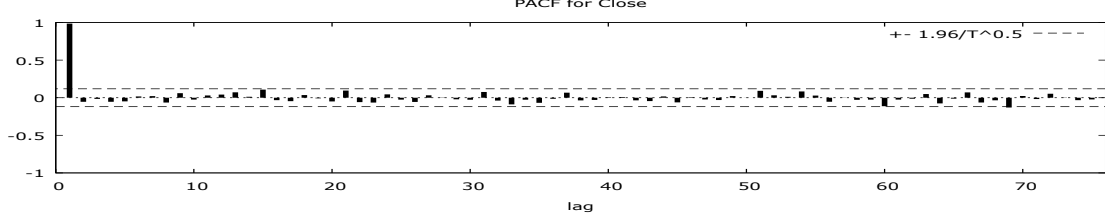

Figure: BSE 200

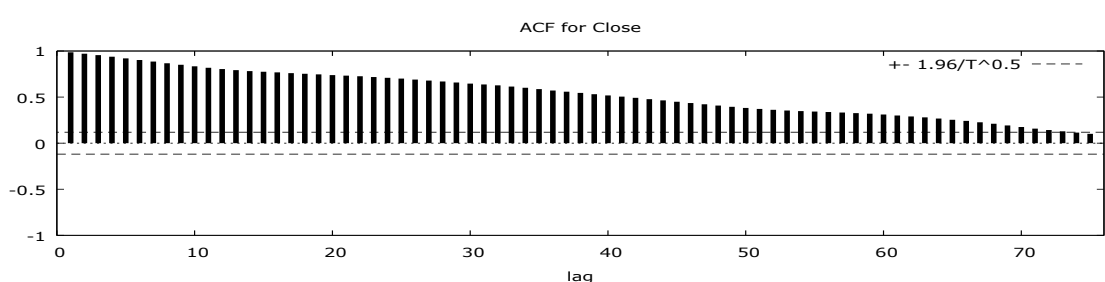

PACF for Close

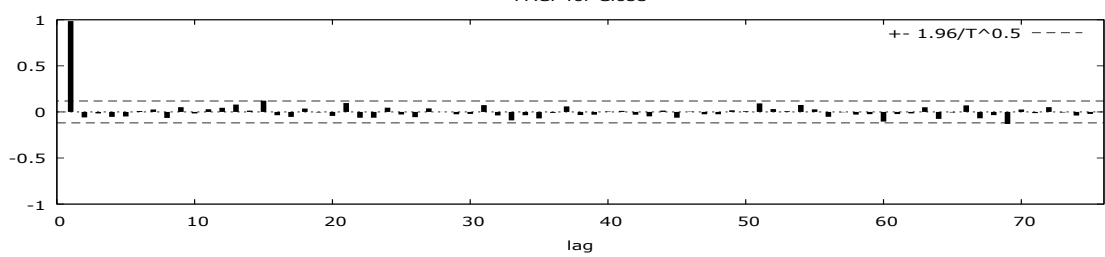

Figure: BSE 500 

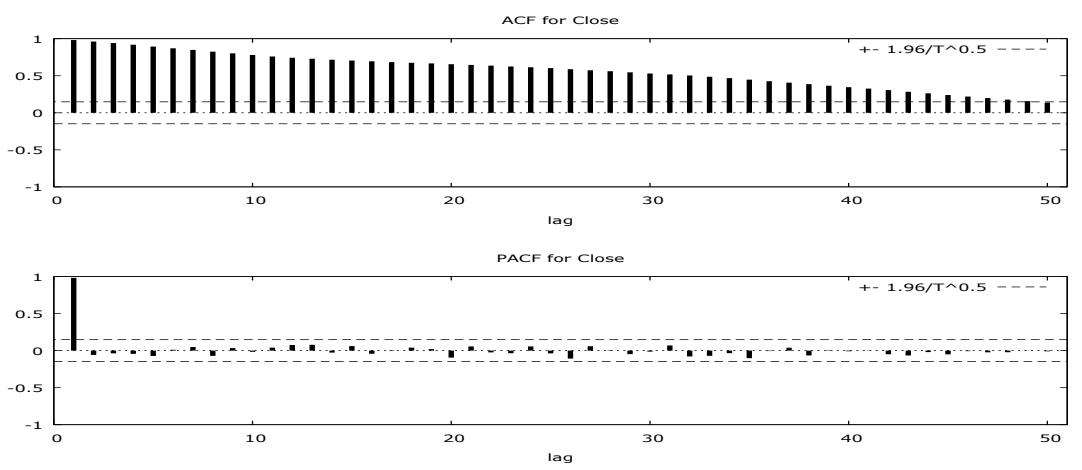

Figure: BSE Mid cap

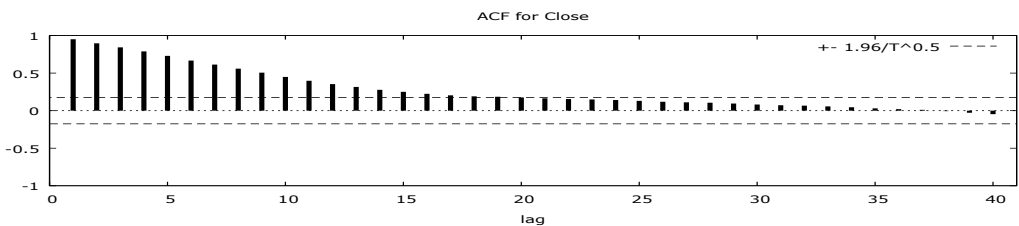

PACF for Close

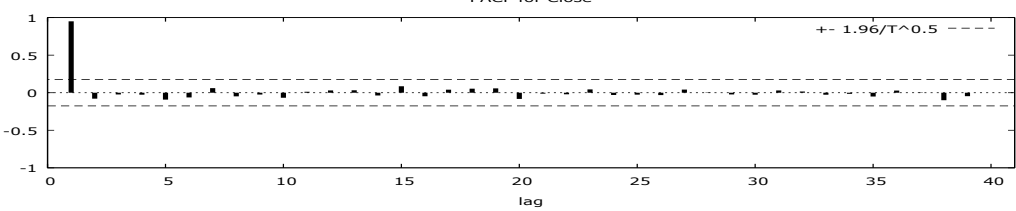

Figure: BSE Small cap

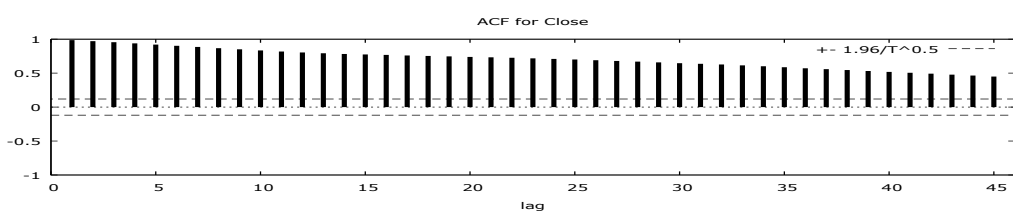

PACF for Close

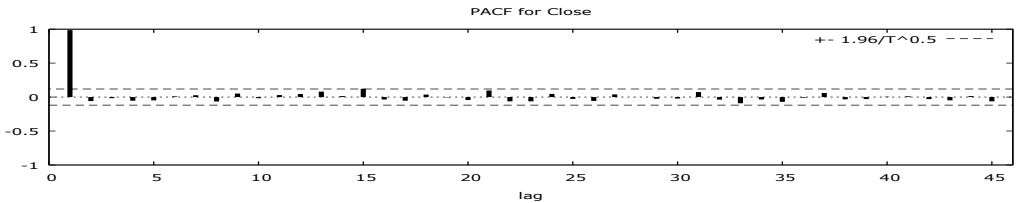

\section{Unit root test}

In this paper Augmented Dickey Fuller (ADF) was selected to test the unit root .This test can be used for testing efficiency of markets because market efficiency demands randomness (non-stationarity) in the prices of securities and unit root test investigates whether the financial time series is non-stationary or not. Unit root test has been conducted on monthly returns series of Sensex 30,BSE 100,BSE 200,BSE 500, BSE Mid cap and BSE Small cap. In table 5 results have shown that there is unit root in monthly return series of all indices at level (without differencing) but all the return series are stationary at Ist difference i.e don't contain unit root. The null hypothesis is accepted in all cases. Thereby being the second test that supports weak form of efficiency in Indian stock market.

Results of Augmented Dickey-Fuller Test (Constant and Trend)

\begin{tabular}{|l|c|c|c|c|}
\hline Variables & Level & p-value & First difference & p-value \\
\hline BSE Sensex Index & -1.92042 & 0.6437 & -6.38125 & $1.262 \mathrm{e}-007$ \\
\hline BSE 100 Index & -1.96789 & 0.6183 & -6.46448 & $7.618 \mathrm{e}-008$ \\
\hline BSE 200 Index & -2.02499 & 0.587 & -6.52884 & $5.129 \mathrm{e}-008$ \\
\hline BSE 500 Index & -3.06258 & 0.1154 & -4.40278 & 0.002111 \\
\hline BSE Mid cap Index & -2.44472 & 0.3562 & -4.47024 & 0.001634 \\
\hline BSE Small cap Index & -2.25573 & 0.4578 & -10.6636 & $1.391 \mathrm{e}-014$ \\
\hline
\end{tabular}




\section{Conclusions}

Results from all the seven tests conducted so far in this research work to test the weak form of market efficiency reveal that there is no normal distribution in any of the time series for the given period under study and that trends can be observed in past prices of all the six indices which, clearly point towards the informational inefficiency of Indian capital market. Hence it can be said, investors may get benefits due to market inefficiency or by seeking advice from fund managers as none of the time series follow Random Walk and Technical analysis of stocks and Indices can be put to use.

\section{Refrences}

[1] Chia-Han Chang, Chu V. Nguyen, Thai D. Nguyen (2012),Testing the Weak-Form Efficient Market Hypothesis: Using Panel Data from the Emerging Taiwan Stock Market, International Journal of Business and Social Science Vol. 3 No.18.

[2] Fama, E., (1970), "Efficient Capital Markets: A Review of Theory and Empirical Work", The Journal of Finance, 25, $383-417$.

[3] Fama, E.F., (1991), "Efficient Capital Markets II", The Journal of Finance, XLVI, 5, December 1991.

[4] Lucio Sarno, Thornton,(2003), The Efficient Market Hypothesis and Identification in Structural VARs, Working Paper 2003032A,http://research.stlouisfed.org/wp/2003/2003-032.pdf

[5] Mitra.S.K,2000,Profitable Trading Opportunity in Indian Stock Market: An empirical Study with BSE-Sensex, Applied Finance, Vol.6(3),36-52.

[6] Pant and Vishnoi 2002,Testing Random Walk Hypothesis for Indian Stock market Indices, Available at www.utiicm.com/2002/pdf.

[7] Ramasastri,2001, Stock market Efficiency-Spectra Analysis, finance India Vol. XV (3). 885-890.

[8] Rutterford, J., 1993, Introduction to Stock Exchange Investment, Second Edition, 281-308, The Macmillan Press Ltd., London.

[9] Saqib\& Hanif, 2012, Testing Weak Form of Efficient Market Hypothesis: Empirical Evidence From South-Asia, World Applied Sciences journal 17(4),414-427.

[10] Sunil.P 1996, "Evidence on Weak Form Efficiency and Day of the Week Effect in the Indian Stock Market”, Finance India, Vol X No.3,605-616.

[11] Simranjeet, Navite and Garima (2008), Testing Weak form of Efficient Market Hypothesis: A Study of National Stock Exchange, Arth Anuesan, Vol.2(2),44-50.

[12] Tim Verheyden ,Filip Van den Bossche,Lieven De Moor (2013), Towards a new framework on efficient markets: A rolling variance ratio test of the adaptive markets hypothesis, Hub Research Papers 2013/04.

[13] Bogdan Dima,L.R. Milos (2009), Testing The Efficiency Market Hypothesis For The Romanian Stock Market, Annales Universitatis Apulensis Series Oeconomica, 11(1).

[14] Meredith Beechey, David Gruen and James Vickery,(2000) The Efficient Market Hypothesis: A Survey, Research Discussion Paper, Reserve Bank of Australia.

[15] Hashem Pesaran (2010), Predictability of Asset Returns and the Efficient Market Hypothesis), University of Cambridge, Discussion Paper No. 5037.

[16] Phil Simmons (2010), Testing the Efficient Market Hypothesis in the Australian Share Market using a Differential Evolutionary Algorithm, Paper prepared for the 39 the Australian Conference of Economists, Sydney, 27-29.

[17] Abdulnasser Hatemi-J, Bryan Morgan (2009), An empirical analysis of the informational efficiency of Australian equity markets, Journal of Economic Studies Vol. 36 No. 5, 437-445.

\section{Annexure:}

\section{Table : Sensex}

Autocorrelation function for Close

$$
\begin{aligned}
& \text { LAG ACF PACF Q-stat. [p-value] } \\
& \begin{array}{ccccc}
1 & 0.9855 * * * & 0.9855 * * * & 267.0973[0.000]
\end{array} \\
& 20.9700 * * * \quad-0.0428 \quad 526.8101[0.000] \\
& \begin{array}{lllll}
3 & 0.9545 * * * & -0.0077 & 779.2014[0.000]
\end{array} \\
& \begin{array}{lllll}
4 & 0.9373 * * * & -0.0629 & 1023.5275[0.000]
\end{array} \\
& \begin{array}{lllll}
5 & 0.9193 * * * & -0.0374 & 1259.4173[0.000]
\end{array} \\
& \begin{array}{lllll}
6 & 0.9022 & * * * & 0.0244 & 1487.4500[0.000]
\end{array} \\
& \begin{array}{lllll}
7 & 0.8856 * * * & 0.0122 & 1708.0227 & {[0.000]}
\end{array} \\
& \begin{array}{llllll}
8 & 0.8677 * * * & -0.0552 & 1920.5563[0.000]
\end{array} \\
& \begin{array}{lllll}
9 & 0.8519 * * * & 0.0668 & 2126.2127 \\
{[0.000]}
\end{array} \\
& \begin{array}{llllll}
10 & 0.8357 * * * & -0.0342 & 2324.8648[0.000]
\end{array} \\
& \begin{array}{llllll}
11 & 0.8201 & * * * & 0.0192 & 2516.8972[0.000]
\end{array} \\
& \begin{array}{lllll}
12 & 0.8059 * * * & 0.0355 & 2703.0494 & {[0.000]}
\end{array} \\
& 13 \quad 0.7938 * * * \quad 0.0606 \quad 2884.3866[0.000] \\
& 14 \quad 0.7829 * * * \quad 0.0259 \quad 3061.4247[0.000] \\
& \begin{array}{lllll}
15 & 0.7751 & * * * & 0.1025 * & 3235.6275[0.000]
\end{array} \\
& 16 \quad 0.7675 * * * \quad-0.0215 \quad 3407.1122[0.000] \\
& \begin{array}{lllll}
17 & 0.7582 * * * & -0.0612 & 3575.1293 & 0.000]
\end{array} \\
& 18 \quad 0.7503 * * * \quad 0.0351 \quad 3740.3085[0.000] \\
& 19 \quad 0.7421 * * * \quad-0.0194 \quad 3902.5564[0.000] \\
& 20 \quad 0.7326 * * * \quad-0.0410 \quad 4061.3024[0.000] \\
& \begin{array}{lllll}
21 & 0.7253 * * * & 0.0862 & 4217.5056 & {[0.000]}
\end{array} \\
& \begin{array}{lllll}
22 & 0.7173 * * * & -0.0500 & 4370.8830 & {[0.000]}
\end{array} \\
& \begin{array}{lllll}
23 & 0.7067 * * * & -0.0713 & 4520.3712[0.000]
\end{array} \\
& 24 \quad 0.6972 * * * \quad 0.0465 \quad 4666.4656[0.000] \\
& \begin{array}{lllll}
25 & 0.6877 * * * & -0.0179 & 4809.1832[0.000]
\end{array}
\end{aligned}
$$




\begin{tabular}{|c|c|c|c|c|}
\hline 6 & 0.6761 & $* * *$ & -0.0489 & $4947.6864[0.000]$ \\
\hline 27 & 0.6641 & $* * *$ & 0.0076 & $5081.8644[0.000]$ \\
\hline 8 & 0.6536 & $* * *$ & 0.0247 & $5212.3397[0.000]$ \\
\hline 9 & 0.6421 & $* * *$ & -0.0208 & $5338.7753[0.000]$ \\
\hline 30 & 0.6294 & $* * *$ & -0.0369 & $5460.7789[0.000]$ \\
\hline 1 & 0.6198 & $* * *$ & 0.0731 & $5579.5613[0.000]$ \\
\hline 32 & 0.6094 & $* * *$ & -0.0307 & $5694.8649[0.000]$ \\
\hline 3 & 0.5961 & $* * *$ & -0.0949 & $5805.6542[0.000]$ \\
\hline 4 & 0.5833 & $* * *$ & -0.0075 & $5912.1828[0.000]$ \\
\hline J & 0.5692 & $* * *$ & -0.0529 & $6014.0831[0.000]$ \\
\hline 6 & 0.5544 & $* * *$ & -0.0217 & $6111.1598[0.000]$ \\
\hline 7 & 0.5425 & $* * *$ & 0.0824 & $6204.5036[0.000]$ \\
\hline 8 & 0.5303 & $* * *$ & -0.0325 & $6294.0559[0.000]$ \\
\hline 39 & 0.5166 & $* * *$ & -0.0451 & $6379.4154[0.000]$ \\
\hline 40 & 0.5038 & $* * *$ & 0.0010 & $6460.9429[0.000]$ \\
\hline 1 & 0.4916 & $* * *$ & 0.0085 & $6538.9237[0.000]$ \\
\hline 42 & 0.4783 & $* * *$ & -0.0306 & $6613.0451[0.000]$ \\
\hline 43 & 0.4645 & $* * *$ & -0.0313 & $6683.2715[0.000]$ \\
\hline 44 & 0.4518 & $* * *$ & 0.0170 & $6750.0091[0.000]$ \\
\hline 45 & 0.4369 & $* * *$ & -0.0720 & $6812.6896[0.000]$ \\
\hline 46 & 0.4231 & $* * *$ & 0.0127 & $6871.7212[0.000]$ \\
\hline 47 & 0.4098 & $* * *$ & -0.0257 & $6927.3562[0.000]$ \\
\hline 48 & 0.3954 & $* * *$ & -0.0312 & $6979.3711[0.000]$ \\
\hline 49 & 0.3816 & $* * *$ & 0.0247 & $7028.0301[0.000]$ \\
\hline 50 & 0.3684 & $* * *$ & -0.0172 & $7073.5921[0.000]$ \\
\hline 51 & 0.3569 & $* * *$ & 0.0913 & $7116.5402[0.000]$ \\
\hline 52 & 0.3461 & $* * *$ & 0.0247 & $7157.1296[0.000]$ \\
\hline 53 & 0.3381 & $* * *$ & 0.0190 & $7196.0278[0.000]$ \\
\hline 54 & 0.3318 & $* * *$ & 0.0936 & $7233.6703[0.000]$ \\
\hline 55 & 0.3265 & $* * *$ & 0.0263 & $7270.2858[0.000]$ \\
\hline 56 & 0.3213 & $* * *$ & -0.0559 & $7305.9065[0.000]$ \\
\hline 57 & 0.3159 & $* * *$ & 0.0097 & $7340.5018[0.000]$ \\
\hline 58 & 0.3099 & $* * *$ & -0.0222 & $7373.9457[0.000]$ \\
\hline 59 & 0.3037 & $* * *$ & -0.0421 & $7406.2104[0.000]$ \\
\hline 60 & 0.2944 & $* * *$ & $-0.1115 *$ & $7436.6843[0.000]$ \\
\hline 61 & 0.2837 & $* * *$ & -0.0114 & $7465.1155[0.000]$ \\
\hline 62 & 0.2734 & $* * *$ & -0.0153 & $7491.6487[0.000]$ \\
\hline 63 & 0.2641 & $* * *$ & 0.0421 & $7516.5218[0.000]$ \\
\hline 64 & 0.2514 & $* * *$ & -0.0747 & $7539.1636[0.000]$ \\
\hline 65 & 0.2382 & $* * *$ & -0.0116 & $7559.5895[0.000]$ \\
\hline 66 & 0.2269 & $* * *$ & 0.0738 & $7578.2134[0.000]$ \\
\hline 67 & 0.2128 & $* * *$ & -0.0504 & $7594.6771[0.000]$ \\
\hline 68 & 0.1979 & $* * *$ & -0.0337 & $7608.9896[0.000]$ \\
\hline 69 & 0.1804 & $* * *$ & $-0.1350 * *$ & $7620.9404[0.000]$ \\
\hline 70 & 0.1636 & $* * *$ & 0.0032 & $7630.8176[0.000]$ \\
\hline 71 & 0.1457 & $* *$ & -0.0359 & $7638.6872[0.000]$ \\
\hline 72 & 0.1305 & $* *$ & 0.0520 & $7645.0326[0.000]$ \\
\hline 73 & 0.1168 & $*$ & 0.0183 & $7650.1419[0.000]$ \\
\hline 74 & 0.1032 & $*$ & -0.0047 & $7654.1522[0.000]$ \\
\hline 75 & 0.0906 & & 0.0258 & $7657.2588[0.000]$ \\
\hline
\end{tabular}

Table: BSE 100

Autocorrelation function for Close
LAG ACF PACF
Q-stat. [p-value]
$\begin{array}{lllll}1 & 0.9860 * * * & 0.9860 * * * & 267.3393 & \text { [0.000] }\end{array}$
$20.9706 * * *-0.0538$
$527.3778[0.000]$
$30.9550 * * *-0.0151$
$780.0532[0.000]$
$\begin{array}{llll}4 & 0.9381 * * * & -0.0539\end{array}$ $1024.7684[0.000]$
$\begin{array}{llll}5 & 0.9199 * * * & -0.0486\end{array}$
$1260.9957[0.000]$
$\begin{array}{lll}6 & 0.9024 * * * & 0.0172\end{array}$
$1489.1683[0.000]$
$70.8858 * * * 0.0214$
$1709.8143[0.000]$
$8 \quad 0.8675 * * *-0.0639$
$1922.2770[0.000]$
$90.8511 * * * \quad 0.0607$
$2127.5638[0.000]$
$10 \quad 0.8346 * * * \quad-0.0248$
$2325.6993[0.000]$
$110.8190 * * * \quad 0.0300$
2517.2477 [0.000]
$20.8049 * * * \quad 0.0419$
$2702.9755[0.000]$
$\begin{array}{llllll}13 & 0.7934 & * * * & 0.0721 & 2884.0985 & {[0.000]}\end{array}$
$14 \quad 0.7826 * * * \quad 0.0130 \quad 3061.0408[0.000]$
$15 \quad 0.7751 * * * \quad 0.1079 * \quad 3235.2728[0.000]$
$\begin{array}{llllll}16 & 0.7677 * * * & -0.0322 & 3406.8301 & {[0.000]}\end{array}$
$\begin{array}{llllll}17 & 0.7590 * * * & -0.0456 & 3575.2076[0.000]\end{array}$
$\begin{array}{lllll}18 & 0.7517 * * * & 0.0354 & 3740.9908 & {[0.000]}\end{array}$
$19 \quad 0.7444 * * * \quad-0.0079 \quad 3904.2410[0.000]$ 


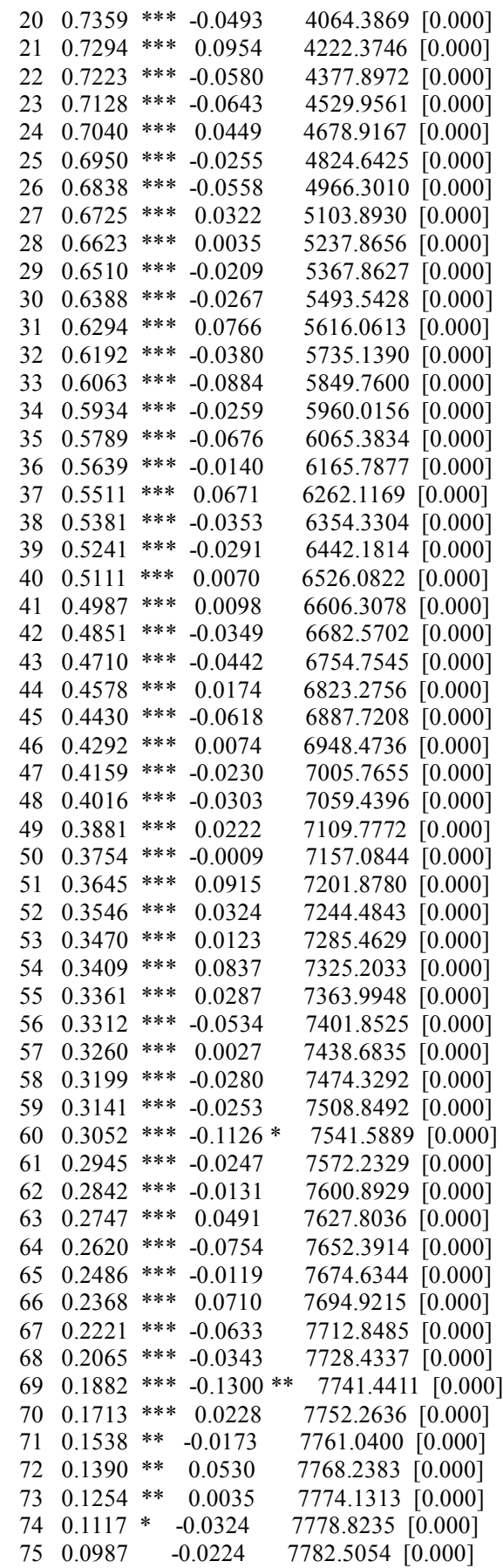

Table : BSE 200

Autocorrelation function for Close

\begin{tabular}{ccccc} 
LAG & ACF & \multicolumn{2}{c}{ PACF } & \multicolumn{2}{c}{ Q-stat. [p-value] } \\
1 & 0.9861 & $* * *$ & $0.9861 * * *$ & $267.4267[0.000]$ \\
2 & 0.9708 & $* * *$ & -0.0592 & $527.5649[0.000]$ \\
3 & 0.9552 & $* * *$ & -0.0162 & $780.3298[0.000]$ \\
4 & 0.9382 & $* * *$ & -0.0536 & $1025.1343[0.000]$ \\
5 & 0.9201 & $* * *$ & -0.0487 & $1261.4494[0.000]$ \\
6 & 0.9024 & $* * *$ & 0.0104 & $1489.6028[0.000]$ \\
7 & 0.8856 & $* * *$ & 0.0266 & $1710.1864[0.000]$ \\
8 & 0.8673 & $* * *$ & -0.0648 & $1922.5518[0.000]$ \\
9 & 0.8506 & $* * *$ & 0.0515 & $2127.5621[0.000]$ \\
10 & 0.8339 & $* * *$ & -0.0163 & $2325.3522[0.000]$ \\
11 & 0.8182 & $* * *$ & 0.0293 & $2516.4939[0.000]$ \\
12 & 0.8040 & $* * *$ & 0.0450 & $2701.7857[0.000]$
\end{tabular}




\begin{tabular}{|c|c|c|c|c|}
\hline 13 & 0.7925 & $* * *$ & 0.0797 & $2882.5197[0.000]$ \\
\hline 14 & 0.7820 & $* * *$ & 0.0144 & $3059.1812[0.000]$ \\
\hline 15 & 0.7751 & $* * *$ & $0.1224 * *$ & $3233.4001[0.000]$ \\
\hline 16 & 0.7682 & $* * *$ & -0.0353 & $3405.1927[0.000]$ \\
\hline 17 & 0.7600 & $* * *$ & -0.0536 & $3573.9965[0.000]$ \\
\hline 18 & 0.7531 & $* * *$ & 0.0363 & $3740.3907[0.000]$ \\
\hline 19 & 0.7463 & $* * *$ & -0.0051 & $3904.4813[0.000]$ \\
\hline 20 & 0.7385 & $* * *$ & -0.0432 & $4065.7909[0.000]$ \\
\hline 21 & 0.7328 & $* * *$ & 0.0965 & $4225.2327[0.000]$ \\
\hline 22 & 0.7262 & $* * *$ & -0.0626 & $4382.4641[0.000]$ \\
\hline 23 & 0.7174 & $* * *$ & -0.0624 & $4536.5237[0.000]$ \\
\hline 24 & 0.7093 & $* * *$ & 0.0463 & $4687.7287[0.000]$ \\
\hline 25 & 0.7007 & $* * *$ & -0.0276 & $4835.8782[0.000]$ \\
\hline 26 & 0.6900 & $* * *$ & -0.0564 & $4980.1282[0.000]$ \\
\hline 27 & 0.6792 & $* * *$ & 0.0386 & $5120.4678[0.000]$ \\
\hline 28 & 0.6693 & $* * *$ & 0.0006 & $5257.2945[0.000]$ \\
\hline 29 & 0.6583 & $* * *$ & -0.0253 & $5390.2086[0.000]$ \\
\hline 30 & 0.6464 & $* * *$ & -0.0211 & $5518.8877[0.000]$ \\
\hline 31 & 0.6372 & $* * *$ & 0.0737 & $5644.4617[0.000]$ \\
\hline 32 & 0.6273 & $* * *$ & -0.0378 & $5766.6459[0.000]$ \\
\hline 33 & 0.6144 & $* * *$ & -0.0911 & $5884.3543[0.000]$ \\
\hline 34 & 0.6013 & $* * *$ & -0.0350 & $5997.5890[0.000]$ \\
\hline 35 & 0.5866 & $* * *$ & -0.0696 & $6105.7963[0.000]$ \\
\hline 36 & 0.5716 & $* * *$ & -0.0097 & $6208.9661[0.000]$ \\
\hline 37 & 0.5586 & $* * *$ & 0.0601 & $6307.9341[0.000]$ \\
\hline 38 & 0.5453 & $* * *$ & -0.0 & $6402.6527[0.000]$ \\
\hline 39 & 0.5312 & $* * *$ & -0.0299 & $6492.9107[0.000]$ \\
\hline 40 & 0.5180 & $* * *$ & 0.0051 & $6579.0985[0.000]$ \\
\hline 41 & 0.5054 & $* * *$ & 0.0113 & $6661.4963[0.000]$ \\
\hline 42 & 0.4918 & $* * *$ & -0.0301 & $6739.8751[0.000]$ \\
\hline 43 & 0.4776 & $* * *$ & -0.0479 & $6814.0970[0.000]$ \\
\hline 44 & 0.4643 & $* * *$ & 0.0146 & $6884.5632[0.000]$ \\
\hline 45 & 0.4495 & $* * *$ & -0.0624 & $6950.8850[0.000]$ \\
\hline 46 & 0.4356 & $* * *$ & 0.0042 & $7013.4441[0.000]$ \\
\hline 47 & 0.4222 & $* * *$ & -0.0254 & $7072.4882[0.000]$ \\
\hline 48 & 0.4081 & $* * *$ & -0.0253 & $7127.9022[0.000]$ \\
\hline 49 & 0.3947 & $* * *$ & 0.0176 & $7179.9602[0.000]$ \\
\hline 50 & 0.3821 & $* * *$ & 0.0079 & $7228.9763[0.000]$ \\
\hline 51 & 0.3714 & $* * *$ & 0.0926 & $7275.4828[0.000]$ \\
\hline 52 & & $* * *$ & 0.0311 & $7319.8296[0.000]$ \\
\hline 53 & 0.3542 & $* * *$ & 0.0083 & $7362.5352[0.000]$ \\
\hline 54 & 0.3481 & $* * *$ & 0.0755 & $7403.9519[0.000]$ \\
\hline 55 & 0.3430 & $* * *$ & 0.0281 & $7444.3642[0.000]$ \\
\hline 56 & 0.3380 & $* * *$ & -0.0527 & $7483.7717[0.000]$ \\
\hline 57 & 0.3324 & $* * *$ & -0.0035 & $7522.0690[0.000]$ \\
\hline 58 & 0.3260 & $* * *$ & -0.0284 & $7559.0840[0.000]$ \\
\hline 59 & 0.3199 & $* * *$ & -0.0239 & $7594.8939[0.000]$ \\
\hline 60 & 0.3109 & $* * *$ & $-0.1047 *$ & $7628.8732[0.000]$ \\
\hline 61 & 0.3003 & $* * *$ & -0.0231 & $7660.7186[0.000]$ \\
\hline 62 & 0.2898 & $* * *$ & -0.0158 & $7690.5143[0.000]$ \\
\hline 63 & 0.2801 & $* * *$ & 0.0507 & $7718.4871[0.000]$ \\
\hline 64 & 0.2672 & $* * *$ & -0.0753 & $7744.0718[0.000]$ \\
\hline 65 & 0.2537 & $* * *$ & -0.0057 & $7767.2464[0.000]$ \\
\hline 66 & 0.2417 & $* * *$ & $=0.0711$ & $7788.3865[0.000]$ \\
\hline 67 & 0.2268 & $* * *$ & -0.0691 & $7807.0800[0.000]$ \\
\hline 68 & 0.2109 & $* * *$ & -0.0346 & $7823.3323[0.000]$ \\
\hline 69 & 0.1923 & $* * *$ & $=-0.1306 * *$ & $7836.9045[0.000]$ \\
\hline 70 & 0.1752 & $* * *$ & $=0.0268$ & $7848.2247[0.000]$ \\
\hline 71 & 0.1578 & $* * *$ & -0.0127 & $7857.4547[0.000]$ \\
\hline 72 & 0.1427 & $* *$ & 0.0519 & $7865.0478[0.000]$ \\
\hline 73 & 0.1289 & $* *$ & -0.0058 & $7871.2698[0.000]$ \\
\hline 74 & 0.1148 & $*$ & -0.0389 & $7876.2287[0.000]$ \\
\hline 75 & 0.1014 & $*$ & -0.0214 & $7880.1193[0.000]$ \\
\hline
\end{tabular}

Table: BSE 500

Autocorrelation function for Close
LAG ACF PACF
Q-stat. [p-value]
$\begin{array}{lllll}1 & 0.9818 * * * & 0.9818 * * * & 171.6019 & \text { [0.000] }\end{array}$
$20.9619 * * * \quad-0.0580$
$337.2545[0.000]$
$3 \quad 0.9409 * * *-0.0363$
$496.6851[0.000]$
$\begin{array}{llll}4 & 0.9187 * * * & -0.0435\end{array}$ $649.5593[0.000]$
$50.8942 * * *-0.0716$ 


$\begin{array}{ccccc}6 & 0.8703 & * * * & 0.0113 & 934.0426[0.000] \\ 7 & 0.8485 & * * & 0.0487 & 1066.7711[0.000] \\ 8 & 0.8247 & * * * & -0.0703 & 1192.9113[0.000] \\ 9 & 0.8024 & * * * & 0.0343 & 1313.0482[0.000] \\ 10 & 0.7802 & * * * & -0.0161 & 1427.3332[0.000] \\ 11 & 0.7602 & * * * & 0.0405 & 1536.4775[0.000] \\ 12 & 0.7432 & * * * & 0.0764 & 1641.4294[0.000] \\ 13 & 0.7298 & * * * & 0.0781 & 1743.2564[0.000] \\ 14 & 0.7165 & * * * & -0.0264 & 1842.0189[0.000] \\ 15 & 0.7059 & * * * & 0.0614 & 1938.4789[0.000] \\ 16 & 0.6950 & * * * & -0.0421 & 2032.5675[0.000] \\ 17 & 0.6842 & * * * & -0.0053 & 2124.3285[0.000] \\ 18 & 0.6748 & * * * & 0.0405 & 2214.1755[0.000] \\ 19 & 0.6667 & * * * & 0.0207 & 2302.4327[0.000] \\ 20 & 0.6557 & * * * & -0.0946 & 2388.3589[0.000] \\ 21 & 0.6461 & * * * & 0.0567 & 2472.3346[0.000] \\ 22 & 0.6365 & * * * & -0.0237 & 2554.3559[0.000] \\ 23 & 0.6250 & * * * & -0.0348 & 2633.9604[0.000] \\ 24 & 0.6146 & * * * & 0.0566 & 2711.4453[0.000] \\ 25 & 0.6031 & * * * & -0.0371 & 2786.5652[0.000] \\ 26 & 0.5883 & * * * & -0.1076 & 2858.5135[0.000] \\ 27 & 0.5741 & * * * & 0.0594 & 2927.4984[0.000] \\ 28 & 0.5613 & * * * & 0.0056 & 2993.8738[0.000] \\ 29 & 0.5465 & * * * & -0.0474 & 3057.2264[0.000] \\ 30 & 0.5304 & * * * & -0.0138 & 3117.3236[0.000] \\ 31 & 0.5178 & * * * & 0.0701 & 3174.9918[0.000] \\ 32 & 0.5037 * * * & -0.0783 & 3229.9402[0.000] \\ 33 & 0.4861 & * * * & -0.0705 & 3281.4846[0.000] \\ 34 & 0.4683 & * * * & -0.0339 & 3329.6522[0.000] \\ 35 & 0.4476 * * * & -0.1019 & 3373.9768[0.000] \\ 36 & 0.4263 & * * * & -0.0059 & 3414.4816[0.000] \\ 37 & 0.4067 & * * * & 0.0389 & 3451.6095[0.000] \\ 38 & 0.3865 & * * * & -0.0651 & 3485.3900[0.000] \\ 39 & 0.3656 & * * * & -0.0050 & 3515.8363[0.000] \\ 40 & 0.3455 * * * & -0.0085 & 3543.2314[0.000] \\ 41 & 0.3267 & * * * & 0.0026 & 3567.9066[0.000] \\ 42 & 0.3059 & * * * & -0.0487 & 3589.6927[0.000] \\ 43 & 0.2838 * * * & -0.0656 & 3608.5945[0.000] \\ 44 & 0.2629 * * * & -0.0197 & 3624.9328[0.000] \\ 45 & 0.2404 & * * * & -0.0498 & 3638.7039[0.000] \\ 46 & 0.2194 & * * * & -0.0072 & 3650.2574[0.000] \\ 47 & 0.1988 & * * * & -0.0230 & 3659.8221[0.000] \\ 48 & 0.1777 & * * & -0.0215 & 3667.5276[0.000] \\ 49 & 0.1574 & * * & -0.0020 & 3673.6197[0.000] \\ 50 & 0.1384 * * & -0.0094 & 3678.3689[0.000]\end{array}$

Table: BSE Mid cap

Autocorrelation function for Close

\begin{tabular}{ccccc} 
LAG & ACF & PACF & \multicolumn{2}{c}{ Q-stat. [p-value] } \\
1 & $0.9509 * * *$ & $0.9509 * * *$ & $115.7660[0.000]$ \\
2 & 0.8967 & $* * *$ & -0.0789 & $219.5426[0.000]$ \\
3 & $0.8427 * * *$ & -0.0233 & $311.9533[0.000]$ \\
4 & 0.7891 & $* * *$ & -0.0260 & $393.6483[0.000]$ \\
5 & $0.7296 * * *$ & -0.0918 & $464.0771[0.000]$ \\
6 & $0.6670 * * *$ & -0.0624 & $523.4211[0.000]$ \\
7 & 0.6134 & $* * *$ & 0.0613 & $574.0369[0.000]$ \\
8 & 0.5594 & $* * *$ & -0.0482 & $616.4922[0.000]$ \\
9 & 0.5059 & $* * *$ & -0.0241 & $651.5231[0.000]$ \\
10 & 0.4492 & $* * *$ & -0.0669 & $679.3734[0.000]$ \\
11 & $0.3979 * * *$ & 0.0130 & $701.4181[0.000]$ \\
12 & $0.3539 * * *$ & 0.0307 & $719.0114[0.000]$ \\
13 & $0.3159 * * *$ & 0.0325 & $733.1575[0.000]$ \\
14 & $0.2778 * * *$ & -0.0368 & $744.1943[0.000]$ \\
15 & 0.2507 & $* * *$ & 0.0862 & $753.2629[0.000]$ \\
16 & 0.2244 & $* *$ & -0.0469 & $760.5940[0.000]$ \\
17 & 0.2042 & $* *$ & 0.0407 & $766.7206[0.000]$ \\
18 & 0.1909 & $* *$ & 0.0537 & $772.1287[0.000]$ \\
19 & $0.1855 * *$ & 0.0582 & $777.2808[0.000]$ \\
20 & $0.1757 * *$ & -0.0825 & $781.9492[0.000]$ \\
21 & $0.1644 *$ & -0.0124 & $786.0752[0.000]$ \\
22 & $0.1543 *$ & -0.0208 & $789.7468[0.000]$ \\
23 & $0.1489 *$ & 0.0444 & $793.1965[0.000]$
\end{tabular}




$\begin{array}{ccccc}24 & 0.1418 & -0.0301 & 796.3580[0.000] \\ 25 & 0.1307 & -0.0255 & 799.0689[0.000] \\ 26 & 0.1186 & -0.0315 & 801.3248[0.000] \\ 27 & 0.1110 & 0.0418 & 803.3202[0.000] \\ 28 & 0.1057 & 0.0050 & 805.1500[0.000] \\ 29 & 0.0947 & -0.0227 & 806.6319[0.000] \\ 30 & 0.0816 & -0.0265 & 807.7453[0.000] \\ 31 & 0.0722 & 0.0304 & 808.6255[0.000] \\ 32 & 0.0668 & 0.0161 & 809.3863[0.000] \\ 33 & 0.0567 & -0.0266 & 809.9408[0.000] \\ 34 & 0.0455 & -0.0146 & 810.3013[0.000] \\ 35 & 0.0303 & -0.0503 & 810.4632[0.000] \\ 36 & 0.0203 & 0.0289 & 810.5366[0.000] \\ 37 & 0.0111 & 0.0048 & 810.5587[0.000] \\ 38 & -0.0062 & -0.0996 & 810.5658[0.000] \\ 39 & -0.0274 & -0.0460 & 810.7049[0.000] \\ 40 & -0.0467 & -0.0000 & 811.1128[0.000]\end{array}$

\section{Table : BSE Small cap}

Autocorrelation function for Close

\begin{tabular}{|c|c|c|c|c|}
\hline LAG & $\mathrm{ACl}$ & & PACF & Q-stat. [p-value] \\
\hline 1 & 0.9861 & $* * *$ & $0.9861 * * *$ & $267.4267[0.000]$ \\
\hline 2 & 0.9708 & $* * *$ & -0.0592 & $527.5649[0.000]$ \\
\hline 30 & 0.9552 & $* * *$ & -0.0162 & $780.3298[0.000]$ \\
\hline $4 c$ & 0.9382 & $* * *$ & -0.0536 & $1025.1343[0.000]$ \\
\hline 50 & 0.9201 & $* * *$ & -0.0487 & $1261.4494[0.000]$ \\
\hline 60 & 0.9024 & $* * *$ & 0.0104 & $1489.6028[0.000]$ \\
\hline 70 & 0.8856 & $* * *$ & 0.0266 & $1710.1864[0.000]$ \\
\hline 80 & 0.8673 & $* * *$ & -0.0648 & $1922.5518[0.000]$ \\
\hline 90 & 0.8506 & $* * *$ & 0.0515 & $2127.5621[0.000]$ \\
\hline 10 & 0.8339 & $* * *$ & -0.0163 & $2325.3522[0.000]$ \\
\hline 11 & 0.8182 & $* * *$ & 0.0293 & $2516.4939[0.000]$ \\
\hline 12 & 0.8040 & $* * *$ & 0.0450 & $2701.7857[0.000]$ \\
\hline 13 & 0.7925 & $* * *$ & 0.0797 & $2882.5197[0.000]$ \\
\hline 14 & 0.7820 & $* * *$ & 0.0144 & $3059.1812[0.000]$ \\
\hline 15 & 0.7751 & $* * *$ & $0.1224 * *$ & $3233.4001[0.000]$ \\
\hline 16 & 0.7682 & $* * *$ & -0.0353 & $3405.1927[0.000]$ \\
\hline 17 & 0.7600 & $* * *$ & -0.0536 & $3573.9965[0.000]$ \\
\hline 18 & 0.7531 & $* * *$ & 0.0363 & $3740.3907[0.000]$ \\
\hline 19 & 0.7463 & $* * *$ & -0.0051 & $3904.4813[0.000]$ \\
\hline 20 & 0.7385 & $* * *$ & -0.0432 & $4065.7909[0.000]$ \\
\hline 21 & 0.7328 & $* * *$ & 0.0965 & $4225.2327[0.000]$ \\
\hline 22 & 0.7262 & $* * *$ & -0.0626 & $4382.4641[0.000]$ \\
\hline 23 & 0.7174 & $* * *$ & -0.0624 & $4536.5237[0.000]$ \\
\hline 24 & 0.7093 & $* * *$ & 0.0463 & $4687.7287[0.000]$ \\
\hline 25 & 0.7007 & $* * *$ & -0.0276 & $4835.8782[0.000]$ \\
\hline 26 & 0.6900 & $* * *$ & -0.0564 & $4980.1282[0.000]$ \\
\hline 27 & 0.6792 & $* * *$ & 0.0386 & $5120.4678[0.000]$ \\
\hline 28 & 0.6693 & $* * *$ & 0.0006 & $5257.2945[0.000]$ \\
\hline 29 & 0.6583 & $* * *$ & -0.0253 & $5390.2086[0.000]$ \\
\hline 30 & 0.6464 & $* * *$ & -0.0211 & $5518.8877[0.000]$ \\
\hline 31 & 0.6372 & $* * *$ & 0.0737 & $5644.4617[0.000]$ \\
\hline 32 & 0.6273 & $* * *$ & -0.0378 & $5766.6459[0.000]$ \\
\hline 33 & 0.6144 & $* * *$ & -0.0911 & $5884.3543[0.000]$ \\
\hline 34 & 0.6013 & $* * *$ & -0.0350 & $5997.5890[0.000]$ \\
\hline 35 & 0.5866 & $* * *$ & -0.0696 & $6105.7963[0.000]$ \\
\hline 36 & 0.5716 & $* * *$ & -0.0097 & $6208.9661[0.000]$ \\
\hline 37 & 0.5586 & $* * *$ & 0.0601 & $6307.9341[0.000]$ \\
\hline 38 & 0.5453 & $* * *$ & -0.0331 & $6402.6527[0.000]$ \\
\hline 39 & 0.5312 & $* * *$ & -0.0299 & $6492.9107[0.000]$ \\
\hline 40 & 0.5180 & $* * *$ & 0.0051 & $6579.0985[0.000]$ \\
\hline 41 & 0.5054 & $* * *$ & 0.0113 & $6661.4963[0.000]$ \\
\hline 42 & 0.4918 & $* * *$ & -0.0301 & $6739.8751[0.000]$ \\
\hline 43 & 0.4776 & $* * *$ & -0.0479 & $6814.0970[0.000]$ \\
\hline 44 & 0.4643 & $* * *$ & 0.0146 & $6884.5632[0.000]$ \\
\hline 45 & 0.4495 & Fit & -0.0624 & $6950.8850[0.000]$ \\
\hline
\end{tabular}

